\title{
ESTRUCTURALISMOS Y CRÍTICA ARGENTINA EN 1970
}

\author{
STRUCTURALISMS AND ARGENTINE CRITICISM IN 1970
}

\author{
Max HIDALGO NÁCHER \\ Universitat de Barcelona \\ maxhidalgo@ub.edu
}

\begin{abstract}
Resumen: El artículo estudia, prestando atención a la circulación internacional de las obras y a los circuitos de producción, cómo el estructuralismo francés se introdujo en Argentina, así como algunos de los usos que la crítica literaria hizo de él alrededor de 1970. De ese modo, se hace posible distinguir, junto al estructuralismo científico representado por Eliseo Verón, un estructuralismo crítico mucho más heterodoxo asociado a nombres como los de Oscar Masotta, Noé Jitrik o Nicolás Rosa.
\end{abstract}

Palabras clave: Estructuralismo. Crítica literaria argentina. Historia de la teoría. Historia intelectual. Teoría literaria francesa.

\begin{abstract}
This article studies, while paying attention to the international circulation of the works and to the production circuits, how french structuralism was introduced in Argentina, as well as some of the ways in which it was used by literary critique around 1970. This allows to distinguish, next to scientific structuralism as represented by Eliseo Verón, a much more heterodox critical structuralism associated to names such as Oscar Masotta, Noé Jitrik or Nicolás Rosa.
\end{abstract}

Key Words: Structuralism. Argentine Literary Criticism. History of Theory. Intellectual History. French Literary Theory. 
Este artículo pretende esbozar algunas de las principales modalidades de introducción del estructuralismo francés en Argentina. Para hacerlo, trataré de señalar los diversos circuitos de producción del mismo y de mostrar, a través de ello, que en Argentina no habrá un estructuralismo, sino dos o tres. Para eso, habrá que diferenciar dos circuitos de producción (uno académico y otro crítico) que hacia 1969 se cruzarán de modo fecundo en la revista Los libros. Por eso, más allá de que los discursos se transformen en su circulación internacional (transformaciones que muchas veces han sido pensadas en términos de degradación), trataré de sugerir además algunas analogías estructurales que se dan entre el caso francés y el argentino. ¿Qué relaciones tiene el estructuralismo con la universidad, la crítica y la comunicación de masas? $\mathrm{O}$, dicho en otros términos, ¿cómo cambia el valor -o hasta la propia naturaleza- de dicho discurso -si es que es posible conferirle una unidad- ya sea leído en un libro, en una revista especializada o en un semanario de difusión masiva?

La circulación de los nombres, las obras y los conceptos permite ver algunas de las particularidades de la lectura y los usos del estructuralismo francés en Argentina. Particularidades que algunos impulsores del estructuralismo leerán como carencias. Ya señalaba en 1970 Eliseo Verón, uno de los principales responsables de la introducción en Argentina de su línea "dura" o científica, lo siguiente:

Reflexionar sobre este desajuste entre la producción de la obra y cierto tipo de consumo, puede sin duda proporcionar importantes enseñanzas. Es obvio además que esa distancia es cualitativamente distinta en el país de origen [...] y en países como el nuestro, donde el "consumo ostentoso" de ciertos libros suele ser el único modo de asociarse (vicariamente) con las orientaciones que predominan en los países centrales (Verón, 1970: 16).

Este artículo pretende delimitar a qué podía referirse Verón en 1970 con ese "consumo ostentoso" y esa asociación "vicaria" con la teoría francesa y, a través de ello y matizando el alcance de esa afirmación, establecer dos modos muy distintos de recepción del estructuralismo en 
Argentina. Uno será la línea teórica (científica, académica: estructuralismo en sentido estricto) promovida por el propio Verón; la otra -más allá de esa "vicariedad" y de ese "consumo ostentoso"-, una línea crítica que no duda en hacer un uso (diríamos profano) de los discursos, e incluso en violentarlo, para conseguir efectos específicos.

1970 será, en ese sentido, una fecha clave que marque un antes y un después en la recepción crítica del estructuralismo, que hasta entonces había tendido a hibridarse en Argentina con la fenomenología. En relación a este punto, para entender la irrupción del estructuralismo en el país conviene tener en cuenta las coordenadas a partir de las cuales podía ser producido. Es decir, definir los discursos hegemónicos y las prácticas críticas del momento. Y, en los años sesenta, las grandes referencias eran marxistas (fuera de la universidad) y fenomenológicas (dentro de ella). Sartre fue para muchos, en ese sentido, la figura híbrida que -aunque nunca llegó a ser central en la universidad- permitía circular de dentro hacia fuera y de fuera hacia dentro de la institución académica ${ }^{1}$. A la crítica literaria, por lo demás, le pasaba algo parecido: se veía partida entre una crítica literaria "inmanentista" (propia de la estilística) y una crítica "documentalista", sociológica y politizante (más cercana al marxismo).

Todo esto es importante porque ambas versiones del estructuralismo van a poner en cuestión, sin duda de modos muy diferentes, las categorías a través de las cuales la obra quedaba escindida por una lectura "interna" y otra "externa" y, con ellas, literatura y política.

\section{EL ESTRUCTURALISMO DE LA CIENCIA}

El estructuralismo -en sentido estricto- sólo es posible en el seno de una estructura universitaria que privilegie la especialización disciplinaria frente a la centralidad o al imperialismo de la filosofía. Su gran apuesta será, en este sentido, la especificidad de los dominios o de las prácticas. Con ello, la irrupción de un modelo científico y disciplinario del estructuralismo por fuerza tendrá que ser tardía -y precaria- en Argentina. Su máximo

1. "En las materias centrales de la carrera la corriente de pensamientos predominante era la fenomenología, con todas sus variantes y derivaciones [...]. Pero si me apurases para que eligiera el nombre más trajinado y, por muchos, el más respetado en las cátedras de Filosofía cuatro décadas atrás, no dudaría: Husserl. Fuera de las aulas, nosotros leíamos a Marx, a Lukács, a Marcuse, a Adorno, a Gramsci. Para mí, el punto de confluencia entre el afuera y el adentro institucional era Sartre" (Lafforgue, 1996: 40). 
promotor será Verón, quien ejercerá una parte importante de su labor a través del Instituto Torcuato di Tella y de la revista LENGUAjes (19741980), publicación de la Asociación Argentina de Semiótica. Verón, quien trabajó con Lévi-Strauss en París entre 1961 y 1963, tratará de importar una versión dura del estructuralismo que, combatiendo los efectos de moda y las desviaciones del ensayismo, consiga fundar un método para las ciencias sociales.

El estructuralismo científico se introducirá en Argentina mayormente a través de la carrera de Sociología que cumplirá, en ese sentido, un papel destacado. Ya en 1957, impulsada por Gino Germani y por el propio Verón, se fundará la primera carrera de Sociología del país en la Universidad de Buenos Aires ${ }^{2}$. En 1959 se introdujo por vez primera a Lévi-Strauss en la docencia, a través de la cátedra de Sociología Sistemática de Germani -quien estaba sin embargo mucho más interesado por las corrientes funcionalistas- $-\mathrm{y}$ de la traducción de un artículo del etnólogo publicado en un Cuaderno del Instituto de Sociología de la misma universidad al año siguiente (Lévi-Strauss, 1960: 25-71). En 1962, Verón publica en Cuestiones de Filosofía una entrevista a Lévi-Strauss (posiblemente, la primera en Argentina ${ }^{3}$ ). La editorial Eudeba publicará, por su parte, Antropología estructural (1958) en 1968 y Tristes trópicos (1955) en 1970.

Para Verón, lo que está en juego es la posibilidad de un tratamiento científico de lo social. En la introducción a su libro recopilatorio Conducta, estructura y comunicación (1963), presenta del siguiente modo el sentido de su tarea:

Estos trabajos giran (tal vez obstinadamente) en torno de distintos aspectos de una misma preocupación (o de un mismo supuesto) acerca de la necesidad y posibilidad

2. Este cambio irá acompañado por la explosión demográfica de la universidad, que permitirá el crecimiento de las nuevas facultades. Dice Lafforgue: "En aquellos tiempos, empleados, docentes y alumnos nos reconocíamos y saludábamos en las aulas y los pasillos; las caras extrañas eran excepción. Había tres carreras troncales: Filosofía, Letras e Historia; pero poco a poco irían adquiriendo autonomía carreras como Geografía o Antropología. Para ponerte un ejemplo bien contundente: cuando yo ingresé a la Facultad, Psicología y Sociología eran materias de Filosofía. Como se sabe, fue Gino Germani quien le dio un decisivo impulso a Sociología, a partir del Instituto preexistente gestó la carrera en el anexo de Florida y Viamonte (año 1957: nacía la primera carrera de Sociología en el país, con sesenta y siete alumnos, que diez años después se habían transformado en dos mil). De allí surgió la flamante Facultad" (Lafforgue, 1996: 39-40).

3. Comité de redacción: Marco Aurelio Galmarini, J. Arthur Gianotti, Jorge Raúl Lafforgue, León Sigal y Eliseo Verón. La entrevista, hecha por el propio Verón, se titula "La antropología hoy: entrevista a Claude Lévi-Strauss" (Lévi-Strauss, 1962: 160-167). 
de elaborar las bases de una teoría de la comunicación social. Puede hablarse, si se prefiere, de "semiología", pero entonces debería entenderse como un nombre cómodo para abarcar muchos resultados, útiles para las ciencias sociales, de una gran cantidad de desarrollos teóricos, metodológicos y empíricos bastante heterogéneos: lingüística, teoría de la información, cibernética, el llamado "estructuralismo" y muchas contribuciones derivadas de lo que los cientificos de habla inglesa prefieren denominar "semiótica". El supuesto adicional es que la convergencia de todas estas líneas nos permite vislumbrar por primera vez la posibilidad, no demasiado utópica, de un tratamiento científico de los fenómenos de significación, cuestión decisiva para la madurez de las ciencias sociales, y que durante toda su infancia estimuló los intentos de diferenciarlas cualitativamente de las demás ciencias (Verón, 1972a: 13-14).

La mayoría de edad de las ciencias sociales pasa, pues, por la asunción del estructuralismo en su vertiente semiológica, la cual permitirá fundar un conocimiento científico de lo social. La relación de intimidad que guarda el sostenimiento de estos planteamientos con la institución universitaria y, más específicamente, con el discurso disciplinar saltan a la vista. Ésta es, a grandes rasgos, la vía de Verón, quien defiende un universalismo de la ciencia sin cegarse a la especificidad latinoamericana:

Salvo el material referido a la evolución y situación actual de la sociología en América Latina, son trabajos que, por sus temas, podrían haber sido escritos en cualquier otra región del mundo. No pienso que esta circunstancia necesite de una explicación particular, pero sí quiero señalarla como indicador de una convicción. Si la reunión de estos trabajos tiene algún sentido unitario, éste reposa, en última instancia, en el hecho de que expresan un firme convencimiento: el de que, en el contexto actual de la ciencia social latinoamericana, es necesario responder a una doble exigencia, cada vez más imperativa: la crítica y 
la construcción de teoría (Verón, 1972a: 18).

Esa exigencia hay que recordarla debido a que "las contradicciones y distorsiones que caracterizan la producción de conocimiento en los países dependientes del Tercer Mundo se manifiestan en cada caso bajo distinta forma" (Verón, 1973: 98). Pues, en efecto, el grave problema con el que se encuentra el estructuralismo en Argentina es la precariedad de una práctica científica que o bien es "nula" o bien "se halla institucionalizada en un grado ínfimo" (Verón, 1973: 102). Con ello, se entiende que esa construcción tenga que llevarse a cabo en Argentina frente a las críticas injustificadas pero, sobre todo, frente a las apropiaciones que desvirtúan la teoría.

\section{EL ESTRUCTURALISMO DE LA CRÍTICA}

Ahora bien, en Argentina, junto a esa visión del estructuralismo que podríamos calificar de dominada en el campo intelectual-, cobrará fuerza desde finales de los años sesenta una crítica estructuralista. Si Verón reivindicaba la universalidad de la ciencia, esta otra versión insistirá en cambio en la particularidad de la actividad crítica. Ésta vendrá posibilitada por varios factores heterogéneos y convergentes que permitirán leer desde fuera de la disciplina ciertos conceptos disciplinarios. Algunas de estas condiciones de posibilidad pasan por la publicación de una parte importante de las traducciones del estructuralismo y la semiótica en lengua castellana ${ }^{4}$. La difusión del pensamiento académico fuera de la universidad a través de nuevas editoriales como Eudeba (Editorial de la Universidad de Buenos Aires), fundada en 1958 y dirigida desde 1959 por Boris Spivacow, y CEAL (Centro Editor de América Latina), también dirigida por él, y que continuó la misma aventura editorial, tras ser interrumpida por el golpe militar, a partir de $1966^{5}$, será también muy importante. Estas editoriales revolucionaron el mundo de la edición, promoviendo grandes tiradas y una distribución generalizada, abriéndose de ese modo a nuevos públicos ${ }^{6}$. En

4. Eliseo Verón afirma la preeminencia de la industria editorial argentina en este punto: "Una buena proporción de los libros que representan el estructuralismo y la semiología, han sido pues introducidos en los países de habla hispana a través de casa editoras argentinas" (Verón, 1973: 98).

5. "Estas editoriales impusieron un estilo de difusión masiva de las disciplinas universitarias, no sólo de las ciencias sociales, y foguearon el debate intelectual” (Sorá, 2004: 278).

6. "Hacia 1965, los libros de Eudeba se vendían en la capital y en el interior a través de $830 \mathrm{~g}$ 
el campo editorial, a esa tendencia se suma la promoción de un circuito de revistas que da cuenta de un auténtico trabajo colectivo de apropiación crítica de las novedades teóricas. Otros factores importantes serán el auge de la clase media y la sociedad de consumo; la renuncia del profesorado a sus puestos en las universidades desde la noche de los bastones rotos de 1966 y la creación de grupos de estudio; la politización de la época, que tiende a interpelar las disciplinas académicas en función de contenidos no académicos; $y$, en último término, la intimidad de la teoría con una práctica crítica que dialoga con la producción literaria viva de la contemporaneidad.

Teniendo presente todo ello, en las próximas páginas me propongo abordar las conexiones y los desacuerdos de esas dos modalidades del estructuralismo, tratando de incidir en la especificidad que tendrá en la crítica. Junto con una visión que lo rechaza calificándolo de moda snob (Masotta sería el snob por excelencia), presentándolo como ideológicamente reaccionario o cómplice de la perpetuación de la dependencia cultural, se darán dos reivindicaciones del estructuralismo que no son estrictamente homologables. Paralelamente a la defensa del estructuralismo científico llevada a cabo por Verón, la opción con más proyección en el campo intelectual consistirá en incorporar las aportaciones de Claude LéviStrauss, pero también las de Roland Barthes, Louis Althusser y Jacques Lacan, y sumarlas a un pensamiento crítico que no por ello va a verse obligado a renegar de lo aprendido en la frecuentación de otras tradiciones críticas como, por ejemplo, la de Jean-Paul Sartre. Esa lectura -que no es necesario calificar de ecléctica, aunque, efectivamente, desbarate el sentido de las polémicas en su contexto de origen- pone ciertas aportaciones de esos autores al servicio de una transformación crítica -y ya no sólo teórica, sino también política y literaria- ya en marcha.

Puede hablarse, en este sentido, de usos libres del estructuralismo. En estos primeros usos que hace la crítica del concepto de estructura se producen, de ese modo, componendas. Es el caso de Procedimiento y mensaje en la novela de Noé Jitrik en 1962 (Córdoba, Universidad Nacional de Córdoba), donde una retórica vagamente formalista vehicula

distribuidoras y librerías, de 40 stands en las facultades, de 41 kioskos propios, 7 de ellos en hospitales, por intermedio de 65 concesionarios, 40 vendedores a crédito, 35 comisionistas, 103 puestos de diarios y revistas, y 2 librerías propias. Hacia el exterior, los libros de Eudeba salían a través de una sucursal en Chile y 419 distribuidores y librerías en América latina, Estados Unidos, Francia, España, Alemania, Japón e Israel” (Sora, 2004: 279). 
una estilística idealista bañada en sartrismo: "Por el camino del examen de los procedimientos de relato elegidos puede llegarse a penetrar la novela como obra literaria a través de uno de sus aspectos, el de las intenciones del autor" (Jitrik, 1962: 138). Oscar Masotta, que es un sartreano militante a mediados de la década, no tiene inconvenientes en citar conjuntamente por entonces -en tanto que autoridades- a Sartre y a Blanchot (Masotta). Algo análogo pasa en la obra de Rosa de esos años. En 1970 publica Crítica y significación, libro en el que se reconoce la amalgama de referencias a Sartre, Merleau-Ponty, Lacan y Lévi-Strauss, así como el intento -más bien superficial- de fundir dichas perspectivas. Así, puede escribir Rosa, sin preocuparse demasiado de en qué planos podría imbricarse efectivamente esa problemática: "El existencialismo como producto cultural de nuestra época no podía permanecer ajeno a la síntesis estructural que se opera en todos campos del conocimiento humano" (Rosa, 1970: 103). Pero eso no es lo fundamental. Más allá de esas postulaciones que en Francia empezaban a mostrarse desde hacía tiempo como insostenibles, lo que interesa a los críticos del momento es tramar una continuidad discursiva que no se basa tanto en el método como en los problemas que se trata de pensar: ¿cómo articular críticamente política y literatura? El concepto de significación será ahí clave. De ese modo, lo que importa en general tanto a Rosa como a Masotta es reconocer que el mundo social está construido a través de una significación que funciona lingüísticamente. Y eso permite pensarlo - ciertamente, de modos diversos- tanto la fenomenología como el estructuralismo ${ }^{7}$.

De ese modo, "significación" es el término que hasta 1970 permite condensar esa constelación crítica en la que todavía pueden darse la mano Sartre y Lévi-Strauss, tal como ocurría por lo demás en el volumen Crítica y significación, de Rosa. El cruce de la significación permitía, así, plantear una lectura social de la literatura que se enfrentara al mismo tiempo al espiritualismo de Sur y a ciertos reduccionismos sociológicos de algunos miembros de Contorno. Y oponerse así al mismo tiempo a practicar una lectura meramente "interna" o meramente "externa" de la literatura.

Lo que da unidad, desde este punto de vista, a esa crítica de inspiración francesa es que concibe la literatura como algo capaz de

7. Años después, aunque cambiará la determinación de una significación que pasará a asociarse al deseo, ésta se seguirá conservando: “Allí donde la palabra del deseo se hace oír, adviene la significación de la obra" (Rosa, 2003: 6). 
movilizar al mismo tiempo la subjetividad y la historia. Es decir, un gesto por el que se neutraliza o se pliega sobre sí la antigua contraposición entre el adentro y el afuera de la obra. Ese gesto, que tiene que desbordar por fuerza el ámbito "objetivo" de la ciencia, une la crítica de Oscar Masotta y de Nicolás Rosa a la de muchos otros de sus compañeros de generación. Ahora bien, esos no podían ser textos "estructuralistas" para Verón.

\subsection{La revista Los libros}

Las dificultades y contradicciones de esa unión entre fenomenología y estructuralismo -que se revelan en el título de Conciencia y estructura (1968) de Masotta- sólo empezarán a hacerse manifiestas a partir del cruce de ambas corrientes del estructuralismo. La revista Los libros (19691976), núcleo privilegiado de introducción no estrictamente académica del estructuralismo en el país, será el principal órgano en el que convivirán ambas tendencias desde 1969. Desde entonces, esas componendas darán paso, en muy poco tiempo, a una transformación teórica que se ejercerá, entre otros dispositivos, a través de lo que José Luis de Diego ha llamado una "crítica de control" (De Diego, 2001: 86): una metacrítica en la que los críticos del momento se leen entre sí y, fechando sus intervenciones, sostienen la necesidad de una constante revisión teórica ${ }^{8}$. A través de esos procedimientos, cabe afirmar que la crítica argentina llega a su madurez teórica ${ }^{9}$. Ese encuentro marcará un antes y un después en la distinción teórica entre estructuralismo y fenomenología, en un contexto en el que Verón y José Sazbón serán en gran medida los máximos promotores de una versión estricta del estructuralismo.

Una mirada rápida al primer año de existencia de dicha publicación da cuenta de esta invasión estructuralista. El número dos presenta en su portada en caracteres destacados el nombre de Lévi-Strauss (al que se dedican tres reseñas, una de ellas de José Sazbón, llamada "Estructuralismo e historia"; el tercero una reseña, fundamental, de José Sazbón sobre "Marx y Sartre"

8. "Los artículos recogidos por Nicolás Rosa en el volumen Crítica y significación (1970) impresionan todavía, en algún sentido, como una muestra estratográfica en la que se ilustra el pasaje del existencialismo sartreano a la lectura del texto literario como reflexión sobre la lengua que lo actualiza. El mismo carácter transicional se advierte en los trabajos recogidos por Noe Jitrik en El fuego de la especie (1971), y en la heterogénea compilación preparada por Jorge Lafforgue, Nueva novela latinoamericana (1969, 1974)" (Prieto, 1989: 23). sito (2015)

9. Respecto a los libros puede consultarse, además del libro de José Luis de Diego ya citado, Espo- 
(Sazbón, 1969: 13-14) en que retoma y hace suya de modo prácticamente literal la crítica de Lévi-Strauss a Sartre en La pensée sauvage (1962); en el cuarto número dedica toda una sección de cuatro reseñas a Althusser; en el cinco Masotta, a propósito de Ernest Jones, sostiene por mediación de Lacan, y bajo el elocuente título "Qué es el psicoanálisis", la primacía del significante en la teoría de Freud; en el seis se publica un escrito de José Sazbón con el título "Qué es el estructuralismo"10, en el que ataca la "operación ideológica" llevada a cabo por "los divulgadores" (Sazbón, 1969: 20) del estructuralismo; en el nueve, la reseña de Verón "Actualidad de un clásico. La moda del estructuralismo", a propósito de Las estructuras elementales del parentesco, junto con otra reseña de Carlos Sastre que, abundando en la misma cuestión, se titula "El negocio editorial al servicio de la ideología"; y en el número diez unas "Aclaraciones en torno a Jacques Lacan" de Oscar Masotta.

Junto a esas reseñas ligadas a las ciencias sociales, se publican otras de lingüística (que aspiran la mayoría de las veces a un acercamiento puramente científico) y otras en las que la politización (ya sea por el tema, ya por el planteamiento) se hace mucho más explícita. Los escritos de crítica literaria se situarán en los primeros años de la revista en esa encrucijada y se nutrirán activamente de las transformaciones de esas tres otras regiones que bien pueden ser pensadas como vectores que pujan entre sí.

Verón participa en Los libros, pero como una voz más entre otros autores como Noé Jitrik, Nicolás Rosa, Oscar Masotta, Josefina Ludmer, Óscar del Barco o Beatriz Sarlo. Uno de sus máximos esfuerzos consistirá, pues, en defender la "pureza" teórica de las ciencias sociales distinguiéndose de dos tendencias: la subsunción de la ciencia bajo el imperativo político (algo que, ligándose desde entonces a la lucha armada, se hará cada vez más frecuente desde 1969 [Terán, 2006: 199]) y su mitificación a través de los efectos de moda.

En julio de 1970, Verón escribirá, a propósito de la edición castellana de Las estructuras elementales del parentesco de Lévi-Strauss, sobre "la moda del estructuralismo". Y ahí afirmará que en Argentina no se cumplen las condiciones necesarias para su correcta asimilación:

\section{Por un doble motivo la invasión "estructuralista" de}

10. Reseña de Antropología estructural, publicado por Eudeba en 1968. 
nuestro contexto intelectual es un fenómeno puramente ideológico. Primero, porque se suele importar los textos más "residuales" de la moda correspondiente, tal como ésta se da en el país central: lo que básicamente compran los editores es el comentario de segundo o tercer orden, el discurso filosófico-especulativo, denominado "estructuralismo"(Verón, 1970: 16).

Libros, pues, como Sentidos y usos del término estructura en las ciencias sociales, de Roger Bastide y otros; El estructuralismo, de JeanMarie Auzias; y Para comprender el estructuralismo, de J.B. Fages (los tres comentados conjuntamente por José Sazbón en "Qué es el estructuralismo" en el número 6 de la revista), a través de los cuales, en vez de promover una puesta en funcionamiento del estructuralismo, se consumiría simplemente su imagen.

Pero había aún un problema mayor para Verón, ligado no sólo a los textos, sino a las condiciones sociales de recepción:

En segundo lugar, la infraestructura de nuestro sistema cultural es tal que, aun en el caso, relativamente excepcional, en que se traducen obras que son auténticos productos de una práctica científica (como las Estructuras elementales), esos textos rara vez pueden ser interpretados en el seno de un trabajo de investigación en marcha, y por lo tanto lo que finalmente resulta consumido de su significación es el peso ideológico que, como todo producto cientifico, la obra contiene (Verón, 1970: 16).

La reseña de Carlos Sastre que se publica en ese mismo número, titulada "El negocio editorial al servicio de la ideología", redunda en la misma idea. En su caso, denuncia "un libro tan temerariamente titulado" (Sastre, 1970: 20 y 22) como Psicoanálisis, existencialismo, estructuralismo. Pero lo cierto es que un poco antes no parecía ninguna temeridad ese gesto. Si son posibles esas componendas se debe, sin duda, a que el estructuralismo ha perdido - o no ha llegado a adquirir-su carácter científico para convertirse en otra cosa. Sastre presenta ese libro como "un alimento más para aquella ideología según la cual todo lo que hay 
puede ser 'integrado' merced a una simple operación al alcance de todos: la suma" (Sartre, 1970: 22).

Así, el problema para Verón va ligado tanto a los textos como a las condiciones sociales de recepción. Como afirmará en 1973, y como ya había dicho respecto al mito del marxismo en Sebreli, el estructuralismo se ha convertido en un objeto más del discurso de masas: "Cuando un tema llega a la sección 'Mundo moderno', 'Ciencia', o 'Arte y Literatura' de un semanario de información, podemos estar seguros de que la orientación ideológica en cuestión se ha convertido ya en una moda circulante en los grupos intelectuales de la burguesía que habitualmente consume dichos medios" (Verón, 1973: 100). Primera Plana es, así, un indicador y un motor al mismo tiempo de esos efectos de moda que llevan hasta sus páginas a Lévi-Strauss o a Philippe Sollers (Primera Plana, 1966: 80) ${ }^{11}$.

Con todo ello, Verón presenta un panorama en el que la episteme se opondría a la doxa, la ciencia a la opinión. Ahora bien, su perspectiva contribuye a desconocer el trabajo específico de la crítica. En el intersticio que se abre entre la ciencia estructural de Verón y el lector de Primera Plana, ¿no hay margen para otros usos del estructuralismo y otras modalidades de lectura? Aquí, precisamente, la crítica literaria tendría algo que decir, pues a partir de 1970, y precisamente gracias a Los libros, ya no será posible esa homologación de fenomenología y estructuralismo que, sin embargo, había abrazado hasta entonces la vanguardia crítica. Por ello mismo, una revista como Los libros hace que la crítica literaria quede separada del espacio periodístico de la comunicación de masas al hacerla comunicar con la vanguardia teórica del momento.

\subsection{Ciencia y circuitos de comunicación}

La crítica de Verón -y la de los otros estructuralistas en sentido estricto- pasará, de hecho, por un criterio de producción. Se trata de una crítica de lo que sería un discurso de masas y un vínculo de consumo. Los comentarios de Verón sobre la doxa estructuralista en 1970 repiten

11. Se lee en ese artículo, titulado "El arte de ser ilegible": "Una religión que se llama lingüistica y que reconoce a Roland Barthes como autoridad suprema y a Ferdinand de Saussure como patriarca. El círculo de elegidos se completa con los filósofos Michel Foucault y Althusser y el psicólogo Lacan. Cada uno en su disciplina 'pretende renovar el pensamiento teórico del siglo XX. La palabra mágica que los une es estructuralismo"” (Primera Plana, 1966: 80). 
la argumentación que unos años antes había elaborado contra ciertos discursos del marxismo. En 1966 Verón dedicaba un duro artículo a Juan José Sebreli con motivo de la publicación de Buenos Aires, vida cotidiana y alienación y Eva Perón, ¿aventurera o militante?, en el que detectaba una transformación inquietante del discurso marxista. Bajo el título "Muerte y transfiguración del análisis marxista" afirmaba que "estos libros contienen los gestos del análisis marxista sin sus resultados concretos" (Verón, 1972b: 260). Y no sólo eso, sino que el análisis de esos libros señalaba que su éxito iba ligado a "una transformación de las pautas de consumo de ciertos grupos de las clases medias y altas, que todo parece indicar que se está produciendo desde hace cuatro o cinco años en Buenos Aires" (Verón, 1972b: 261). La revista Primera Plana, que publicó su primer número el 13 de noviembre de 1962, sería el exponente cultural de la emergencia de ese nuevo público argentino que consume cultura a través de nuevos circuitos de publicación, tal como ocurriría en la línea de Time en los Estados Unidos o en L'Express o France-Observateur en Francia.

La tesis de Verón respecto a los libros de Sebreli era contundente: "Su aparición señala la institucionalización del mito del análisis marxista en nuestro medio cultural" (Verón, 1972b: 260). Esa noción de mito era utilizada, por lo demás, en términos estrictamente barthesianos. Verón establecía así una relación entre mito y cultura de masas para probar que en la lectura de los libros de Sebreli "se trata del consumo masivo" (problema del circuito de comunicación y del mercado) "de una creación mítica” (Verón, 1972b: 263) (problema propiamente discursivo). Verón, gran defensor del estructuralismo científico, en un sentido fuerte, en el contexto argentino, sólo podrá defenderlo a condición de protegerlo de esas lecturas profanas que -míticas o no- desplazan el interés científico en pos de otros intereses. De ese modo, lo que estaba en juego eran dos circuitos de producción y circulación de los discursos; y si partimos de la base de que un discurso no puede ser un discurso con independencia de sus condiciones de producción y recepción, se trataría de dos discursos diferentes. Jean-Claude Milner lo ha analizado con una cierta precisión respecto al estructuralismo francés: a mediados de la década de los sesenta pierde fuerza el estructuralismo como proyecto científico hasta agotarse, siendo relevado en ese mismo momento por el éxito mundial y periodístico 
del "estructuralismo"12. Como ha señalado este autor, "on peut donc dater en 1968 la fin du structuralisme comme programme de recherches dans son ensemble, étant admis que l'ébranlement a commencé plus tôt [...]. Mais comme ce déclin s'accompagnait de succès médiatiques et institutionnels, la perception fut troublée" (Verón, 1972b: 279). Ese paso de la episteme a la doxa estructural coincide aproximadamente, por lo demás, con las calificaciones (sumamente vagas) de "postestructuralismo" que se han aplicado posteriormente a dicho objeto.

La pretensión del estructuralismo en sentido estricto era fundar una ciencia de lo real. En Argentina, a pesar de Verón, entrará con fuerza una segunda modalidad del estructuralismo que, más allá de la aplicación de los estrictos criterios de cientificidad, privilegiará la relación crítica sobre la propiamente teórica. Y que -repito-en Francia también existía como un movimiento crítico constituido en los intersticios del periodismo y de la academia. Con Barthes y con Foucault, con Masotta y con Rosa, surgirá un nuevo estructuralismo que participará de la especulación filosófica, de las luchas políticas y de la invención literaria y que -por sus nuevos circuitos de circulación- quedará por fuerza redoblado - pero no abolido- por el mito.

\section{ESTRUCTURALISMO Y LITERATURA}

Con todo ello, puede afirmarse que el "estructuralismo" de la crítica argentina no sería eminentemente teórico (científico), sino crítico y literario. El propio Verón lo ha señalado al afirmar que, lejos de introducirse a través de la antropología, "a la Argentina llegan en cambio las ideas estructuralistas, desprendidas de la práctica que las engendrara" (Verón, 1973: 104). Los límites de su perspectiva-que aspira a un rigor que abola la especulación de su seno- se revelan en una nota al pie del artículo anteriormente citado. Pues la mitología del estructuralismo se emparentaría con una mitología de la lectura que, sin duda, habría surgido en la crítica de un cierto trato íntimo con la literatura. Y que, por qué no decirlo, tendría en Barthes -en ese Barthes al que Lévi-Strauss rechazó dirigir la tesis doctoral- a su gran promotor. Escribe Verón:

12. "On peut donc dater en 1968 la fin du structuralisme comme programme de recherches dans son ensemble, étant admis que l'ébranlement a commencé plus tôt [...]. Mais comme ce déclin s'accompagnait de succès médiatiques et institutionnels, la perception fut troublée" (Milner: 279). 
Por contraste con la "mitología de la lectura" (que es una variante importante de la actual ideología "estructuralista"), quisiera que aqui el término lectura se interpretara ingenuamente, sin significados ocultos ni connotaciones sofisticadas: "lectura" como lo que uno hace cuando se sienta y lee un libro (Verón, 1970: 18).

Que Verón pueda denunciar esa “mitología de la lectura” en 1970, lejos de representar una "mala recepción" del estructuralismo, indica que en Argentina llegaban de modo prácticamente inmediato los ecos de los debates parisinos del momento. De ese modo, la situación descrita por Verón tiene su paralelismo en las transformaciones que se están llevando a cabo poco antes en Francia. No conviene olvidar que en Francia tenderán a confundirse ambas perspectivas a partir de la segunda mitad de los años sesenta. Junto con Lévi-Strauss, A. J. Greimas será uno de los máximos defensores de un estructuralismo científico que reniega de los usos no disciplinarios de los conceptos provenientes de la lingüística. En 1966 Greimas publica su Semántica estructural, en la que se lee:

El inconveniente inevitable de la gloria [...] designado con el nombre de "trivialización", se caracteriza por la distorsión de las estructuras metodológicas de una disciplina y por la neutralización de las oposiciones, a menudo fundamentales, entre sus conceptos. Una terminología lingüistica empobrecida y desfigurada se difundió en ciertas revistas de vanguardia: al lingüista le costaba trabajo reconocer alli a sus propias criaturas (Greimas, 1966: 8).

Verón defiende lo mismo que ya defendía Greimas unos pocos años antes en Francia: un cierre disciplinario. Ahora bien, ese estructuralismo científico o semiológico tendrá un carácter dominado en el campo intelectual del momento. Y la "mitología de la lectura" a la que se refiere, más que un producto periodístico autóctono de Argentina, proviene en gran parte del trabajo llevado a cabo en torno al grupo "Tel quel", promotor -entre otras muchas obras- del volumen Théorie d'ensemble (1968), traducido al 
castellano en 1971 por Seix Barral y cuyos artículos fueron fotocopiados y leídos por las nuevas generaciones de críticos del momento. Como escribe Adolfo Prieto, en los años sesenta "se empezaba a invocar, como contraseña, la posesión de algún ejemplar de la revista Tel quel" (Prieto, 1989: 22). Esa situación permite entender la pasión que, a principios de los setenta, pudieron despertar en Roberto Retamoso, entonces un joven alumno de veintitantos años, las clases de Rosa en la Universidad Nacional de Rosario:

Las tradiciones más importantes de la teoría literaria tenían que ver con el campo de la lingüistica y la inmanencia del análisis textual o con la perspectiva de la crítica sociológica, de espiritu marxista, que tenía que ver con los abordajes contextuales, y que de algún modo llevaba a perder de vista la especificidad del texto. Entonces, Nicolás [Rosa] nos dio acceso a Kristeva, y al posestructuralismo en general, lo que representaba una perspectiva teórica que permitía vincular esas dos tradiciones (Rematoso, 2013) ${ }^{13}$.

Tanto la incorporación de nuevos públicos - a través de publicaciones como Primera plana - como la politización creciente de los años sesenta y setenta llevarán, por fuerza, a descentrar el discurso académico. Eso, unido a la inestabilidad de unas estructuras universitarias que tendrán que afrontar los estragos de las dictaduras, hará que el estructuralismo en sentido estricto tenga serios problemas para sostener esa "pureza" que para él reclamaba Verón. Frente a esa modalidad del estructuralismo, en Argentina dominará, ante la "guerra sucia" que "despobló los claustros universitarios y ahogó la posibilidad del pensamiento crítico", lo que Nicolás Rosa llamó "una crítica resistente" (Rosa, 1993: 162). Una crítica estratégica, con una conciencia relativa de la propia situación, de los propios límites; y que, por lo tanto, se concibe a sí misma como provisional y transformadora. Entre el estructuralismo científico y el periodístico, dicha actitud crítica se deja resumir en la siguiente afirmación de Rosa (que, sin negarlo por completo, bien podía leerse como un cambio de énfasis y una apostilla crítica al proyecto de Verón y, con ella, a cualquier pretensión

13. Puede consultarse también Retamoso, "Kristeva, más de treinta años después" (2007). 
de construir una ciencia de lo universal): "Somos lectores de lo universal, pero escritores de lo particular".

\section{REFERENCIAS BIBLIOGRÁFICAS}

DE DIEGO, J. L. (2001). “QQuién de nosotros escribirá el Facundo?”. En Intelectuales y escritores en Argentina (1970-1986). La Plata: Al Margen.

ESPOSITO, F. (2015). "La crítica moderna en Argentina: la revista Los Libros (1969-1976)". Orbis Tertius XX.21, 1-8. Disponible en línea: http://www.orbistertius.unlp.edu.ar/files/journals/7/articles/6004/ public/6004-11772-1-PB.pdf [05/01/2017].

GREIMAS, A.J. (1987). Semántica estructural. Investigación metodológica. Madrid: Gredos. (Sémantique structurale, 1966).

JITRIL, N. (1962). Procedimiento y mensaje en la novela. Córdoba: Universidad Nacional de Córdoba.

LAFFORGUE, J. (1996). Entrevista de Carlos Dámaso Martínez a Jorge Lafforgue. "La historia siguió, sigue y seguirá". Espacios de crítica y producción 19-20, 39-44.

LÉVI-STRAUSS, C. (1960). "La noción de estructura en antropología". Boletín del Instituto de Sociología de la Facultada de Filosofía y Letras de la Universidad de Buenos Aires 19, 25-71.

(1962). "La antropología hoy: entrevista a Claude Lévi-Strauss". Cuestiones de Filosofía 2/3, 160-167.

MASOTTA, O. (1963). "Sobre crítica literaria en Argentina". En Conciencia y estructura (1968). Buenos Aires: Eterna Cadencia, 2010.

MILNER, J-C. (2008). "Le paradigme: programme de recherches et mouvement d'opinion". En Le périple structural. Figures et paradigme. Paris: Verdier.

PRIETO, A. (1989). "Estructuralismo y después". Punto de vista 34, XII, 22-25.

Primera Plana (1966). "El arte de ser ilegible". Primera plana 207, 80.

RETAMOSO, R. (2007). "Kristeva, más de treinta años después”. Dossier de Estudios Semióticos. La trama de la comunicación 12, 161-171. 
(2013). "Entrevista personal". Rosario, 15 de julio.

ROSA, N. (1970). Crítica y significación (David Viñas, Sartre y Genet, Mafud, Cabrera Infante). Buenos Aires: Galerna.

(1993). "Veinte años después o la "novela familiar" de la crítica literaria". Cuadernos hispanoamericanos 517-519, 161-186.

(2003). "Estos textos, estos restos". En La letra argentina (crítica 1970-2002). Buenos Aires: Santiago Arcos.

SASTRE, C. (1970). "El negocio editorial al servicio de la ideología". Los libros 9,20 y 22.

SAZBÓN, J. (1969). "Qué es el estructuralismo". Los libros 6 y 20.

SORÁ, G. (2004). "Editores y editoriales de ciencias sociales: un capital específico". En Federico Neiburg y Mariano Plotkin (comp.), Intelectuales y expertos. La constitución del conocimiento social en la Argentina. Buenos Aires: Paidós.

TERÁN, O. (2006). De utopías, catástrofes y esperanzas: Un camino intelectual. Buenos Aires: Siglo Veintiuno.

VERÓN,E.(1970). “Actualidad de un clásico. La moda del estructuralismo". Libros 9, 14 y 18.

(1972a). "Introducción”. En Conducta, estructura y comunicación. Buenos Aires: Tiempo Contemporáneo. Ed. corregida y aumentada respecto a la publicada en Jorge Álvarez en 1963.

(1972b). "Muerte y transfiguración del análisis marxista". En Conducta, estructura y comunicación. Buenos Aires: Tiempo Contemporáneo. Ed. corregida y aumentada respecto a la publicada en Jorge Álvarez en 1963.

(1973). "Acerca de la producción social del conocimiento: el "estructuralismo" y la semiología en Argentina y Chile". LENGUAjes. Revista de lingüística y semiología 1, 96-125.

Recibido el 28 de febrero de 2017.

Aceptado el 9 de marzo de 2017. 